\title{
6
}

\section{SERVIÇO SOCIAL, EDUCAÇÃO PROFISSIONAL E QUESTÃO RACIAL: OS DESAFIOS DO ACESSO E PERMANÊNCIA}

\author{
Social work, professional education and racial issue: the challenges of access and \\ permanence
}

\section{Zora Yonara Torres Costa*}

https://orcid.org/0000-0003-4475-2282

Marlene Teixeira Rodrigues**

https://orcid.org/0000-0001-9418-7192

\section{RESUMO}

O presente artigo objetiva promover o debate sobre a educação profissional pública, no que se refere ao acesso dos estudantes negros e negras e a intervenção das e dos Assistentes Sociais neste espaço sócioocupacional. No passado, a educação profissional pública foi instituída de modo a atender aos filhos dos desfavorecidos, sendo que o acesso da população negra à educação profissional sempre foi ínfimo, segundo pesquisadores. Na atualidade, com a presença de políticas de ação afirmativa e de assistência estudantil o cenário se modifica; porém mesmo com tais políticas a desigualdade racial persiste, guardando elementos conservadores que operam para manutenção da ordem vigente. Uma realidade que emerge imbricando o racismo ao viés classista e sexista, típicos da formação social brasileira que se (re)atualiza continuamente, como se vê na disparidade no nível de instrução entre negros e não negros. Hoje, podemos observar que o acesso das/os estudantes negros e negras na educação profissional pública engloba aspectos conjunturais e estruturais, com contradições e antagonismos inerentes a dinâmica societária. Nesse cenário, as e os Assistente Sociais inseridos na educação profissional pública, que são demandados, cotidianamente, a atuar em manifestações da questão social, dentre as quais, se destaca a desigualdade racial, têm diante de si, um desafio cotidiano tendo em vista uma prática antirracista, não sexista e pautada na garantia de direitos.

\section{PALAVRAS-CHAVE}

Educação profissional. Questão racial. Serviço social. Acesso. Permanência.

\section{ABSRACT}

This article aims to promote the debate on public professional education, regarding the access of black and black students and the intervention of social workers in this socio-occupational space. In the past, public professional education has been instituted to serve the children of the disadvantaged, and the black

\footnotetext{
* Assistente Social. Doutoranda pelo Programa de Pós-Graduação em Política Social (PPGPS), Departamento de Serviço Social, Instituto de Ciências Humanas da Universidade de Brasília (UnB, Brasília (DF), Brasil). Campus Universitário Darcy Ribeiro, Instituto Central de Ciências (ICC NORTE - Asa Norte, Brasília (DF), CEP.: 70910-900. E-mail: zorayona@gmail.com.

** Assistente Social. Doutora em Sociologia. Professora do Programa de Pós-Graduação em Política Social Universidade de Brasília (UnB, Brasília (DF), Brasil). Campus Universitário Darcy Ribeiro, Instituto Central de Ciências (ICC NORTE - Asa Norte, Brasília (DF), CEP.: 70910-900. E-mail: martebr@gmail.com.
}

DOI 10.22422/temporalis.2020v2on40p268-283

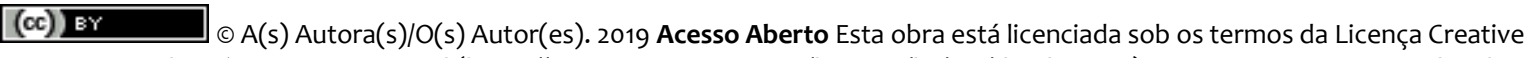
Commons Atribuição 4.0 Internacional (https://creativecommons.org/licenses/by/4.o/deed.pt_BR), que permite copiar e redistribuir o material em qualquer suporte ou formato, bem como adaptar, transformar e criar a partir deste material para qualquer fim, mesmo que comercial. O licenciante não pode revogar estes direitos desde que você respeite os termos da licença.

Temporalis, Brasília (DF), ano 20, n. 40, p. 268-283, jul./dez. 2020. | ISSN 2238-1856 


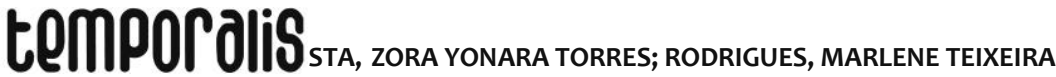

population's access to professional education has always been minimal, according to researchers. Nowadays, with the presence of affirmative action policies and student assistance, the scenario changes; however, even with such policies, racial inequality persists, guarding conservative elements that operate to maintain the prevailing order. A reality that emerges, imbuing racism with a classist and sexist bias, typical of Brazilian social formation that is (re) continually updated, as seen in the disparity in the level of education between blacks and non-blacks. Today, we can observe that the access of black and black students in public professional education encompasses conjuncture and structural aspects, with contradictions and antagonisms inherent to corporate dynamics. In this scenario, the social workers inserted in public professional education, who are demanded, daily, to act in manifestations of the social issue, among which, racial inequality stands out, have before them, a daily challenge in view of an anti-racist practice, not sexist and based on the guarantee of rights.

\section{KEYWORDS}

Professional education. Racial issue. Social work. Access. Permanence.

Submetido em: 21/4/2020.

Aceito em: 10/11/2020.

\section{INTRODUÇÃO}

A população negra ainda vive, majoritariamente, em situação de vulnerabilidade social, suscetível a mortes violentas, a agressões e abusos de autoridade, bem como invisível, nas suas especificidades, para as ações das políticas públicas, principalmente na área da saúde, educação, assistência social, habitação, nas artes e na mídia (EURICO, 2013, p. 307)

$\mathrm{D}$ ata do início do século XX uma das primeiras inciativas estatais que permitiu aos negros acesso à educação. O marco histórico é o ano de 1909, momento de criação da rede de educação profissional pública no Brasil. Neste ano, por meio do Decreto $n^{\circ} 7.566$, de 23 de setembro (BRASIL, 1909), o então presidente Nilo Peçanha criou 19 escolas de artífices e ofícios, para atender aos filhos dos desfavorecidos. Importante destacar que anterior a este ano, já havia iniciativas relacionadas a educação profissional privada, como o sistema educacional jesuíta, as casas de educandos de artífices e liceus de artes e ofícios (MANFREDI, 2002).

A modernização tecnológica e a chegada da indústria no Brasil trouxeram à educação outros ares e a educação profissional passou a ser um caminho para a formação da população, propiciando conhecimento e instrução para os filhos dos trabalhadores brasileiros, além de colocar o Brasil em um patamar de progresso e modernizar o país frente as potências mundiais. Destarte, a qualificação profissional se constituiu como uma oportunidade de ascensão também para a população negra, porque muitos destes estavam em situação de pobreza e abandono social na Primeira República. Assim, a qualificação profissional e o acesso à educação profissional por parte de negros e negras se materializou, nesse contexto, ainda que o ingresso desta população tenha sido baixo, conforme destacam Silva e Araújo (2005).

Assim, a educação profissional foi um dos espaços de instrução para a população negra, porém, sabemos também que não havia interesse por parte do conjunto da sociedade em promover uma reparação histórica real após a abolição. Ao contrário foi cultivado e colocado em prática o projeto societário para manter a desigualdade racial, materializada na "[...] atribuição de tratamento diferenciado a membros de grupos racialmente identificados [...]" (ALMEIDA, 2019, p. 32), situação que perdura até os dias atuais. 


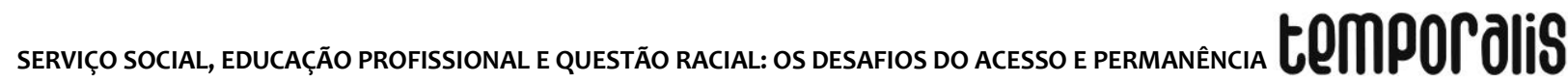

A aprovação da Constituição Federal do Brasil, em 1988, muitas décadas após o período que inaugurou a educação profissional pública, constitui outro momento importante para o reconhecimento e enfrentamento da desigualdade racial por parte do Estado. $O$ advento da "Constituição Cidadã", que marca a retomada da democracia no País, reconheceu, em seu Artigo $5^{\circ}$, que " [...] todos são iguais perante a lei, sem distinção de qualquer natureza, garantindo-se aos brasileiros e aos estrangeiros residentes no País a inviolabilidade do direito à vida, à liberdade, à igualdade, à segurança e à propriedade" (BRASIL, 1988). Afirma-se assim, no texto constitucional, a igualdade independente de "raça". Este reconhecimento engendrou um diversificado leque de políticas e ações voltadas à reparação, que foram delineadas a partir da ação de sujeitos políticos, como o movimento negro, que teve um papel fundamental na luta pelo acesso à educação, reconhecida como um direito de todas e todos e dever do Estado, no Artigo 205 da CF.

Verificamos que nas últimas décadas o cenário da educação profissional ganhou nova perspectiva. O marco legal importante neste tema é a Lei de Diretrizes e Bases (LDB) (Lei $n^{\circ}$ 9.394/96) (BRASIL, 1996) - que, em nova redação dada aos artigos 37, 39, 41 e 42, garantiu a integração da educação profissional aos diferentes níveis e modalidades de educação e às dimensões do trabalho, da ciência e da tecnologia ainda mais.

A educação profissional, como política pública, foi sendo materializada em meio à conjuntura política e socioeconômica dessas últimas três décadas, revelando contradições e desafios. A expansão da educação profissional, por meio da criação dos Institutos Federais de Educação Profissional e Tecnológica, significou mudanças substantivas no início do século XXI, com a criação de uma “[...] nova institucionalidade e engenharia da educação profissional [que] se concretizou a partir da Lei 11.892/2008 (...). Os Institutos Federais de Educação, Ciência e Tecnologia (IFs) deram materialidade a este processo, que não só é institucional como também territorial" (GOUVEIA, 2016). A criação do Institutos Federais possibilitou a interiorização da educação profissional, porém sempre coadunando com a proposta de mercado local onde os Institutos fossem instalados, revelando a persistência da dimensão econômica como fator primordial de definição da interiorização. Processo que requer um olhar crítico, tendo em vista a questão do enfrentamento da desigualdade nos municípios contemplados.

Não obstante os avanços, as ações não foram capazes, todavia, de superar a imensa disparidade educacional entre jovens negros e não negros, como se observa nos números da Pesquisa Anual de Amostra de Domicílios Contínua (PNAD), do Instituto Brasileiro de Geografia e Estatística (IBGE), de 2018:

Na análise segundo o sexo e a cor ou raça, nota-se que, de maneira geral, a
condição de estudo e a situação de ocupação entre esses jovens permaneceu
similar entre 2017 e 2018 . Entre as mulheres, $28,4 \%$ não estavam ocupadas, nem
estudando ou se qualificando, percentual estável frente a 2017 . Entre os
homens, $17,6 \%$ estavam nessa condição ( 0,2 p.p. a mais que em 2017$)$. Por outro
lado, $28,1 \%$ das mulheres e $41,7 \%$ dos homens apenas trabalhavam e $30,2 \%$ das
mulheres e $27,0 \%$ dos homens apenas estudavam ou se qualificavam. Entre as
pessoas brancas, $16,1 \%$ trabalhavam e estudavam ou se qualificavam, percentual
estatisticamente igual ao de 2017 , porém maior que entre as pessoas de cor
preta ou parda, $11,9 \%$. O percentual de pessoas brancas apenas trabalhando

${ }^{1}$ Importante pontuar que raça está entre aspas, pois destacamos o termo chamando atenção aos leitores e leitoras que aqui tem uma conotação social e histórica e não biologicista.

Temporalis, Brasília (DF), ano 20, n. 40, p. 268-283, jul./dez. 2020. | ISSN 2238-1856 


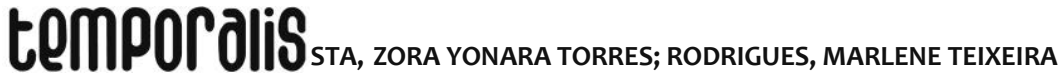

$(36,1 \%)$ e apenas estudando (29,3\%) também superou o de pessoas de cor preta ou parda, $34,2 \%$ e $28,1 \%$ respectivamente. Consequentemente o percentual de pessoas pretas ou pardas que não trabalhavam nem investiam em educação foi 7,3 p.p. maior que das pessoas brancas (IBGE, 2018, p.12).

Esse cenário revela alguns dos desafios e complexidades que caracterizam a dinâmica da desigualdade racial no Brasil e que exigem criticidade por parte das/os assistentes sociais, que atuam no espaço sócio-ocupacional da educação profissional pública. Como assinala Marilda, devemos "[...] pensar o exercício profissional em suas implicações na órbita das condições de relações de trabalho em que se inscreve" (IAMAMOTO, 2001, p. 29). Nesse sentido é imprescindível compreender que, não obstante a incorporação ainda significativa da ideia de democracia racial, no Brasil, a realidade é a desigualdade racial que é parte do nosso cotidiano, embora frequentemente seus contornos possam passar desapercebidos, ser naturalizados, em decorrência da vigência daquela. Este é uma tema especialmente importante para o Serviço Social pois, como mostra Márcia Eurico (2013, p. 301), "[... ] a percepção dos assistentes sociais acerca da questão racial e dos mecanismos de reprodução do racismo no interior da sociedade brasileira ainda está bastante distorcida [...]" e a categoria de assistentes sociais, não tem um conhecimento adensado acerca da questão racial. A atuação das/o profissionais de Serviço Social requer pois, estar atento para não sucumbir ao pensamento idealista.

Nesse contexto, vale destacar os esforços de profissionais de Serviço Social que, há algum tempo, entendendo que as relações raciais são mediações da realidade, presentes nos espaços sócio-ocupacionais, começaram, a pesquisar sobre a questão, dentre os quais se destacam: Magali da Silva Almeida, Fátima Cristina Rangel Sant'Ana, Maria José Pereira, Matilde Ribeiro, Selma Inês Alves de Deus, Marlise Vinagre Silva, Elizabeth Pinto e Cristina de Fátima Guimarães.

Mais recentemente, vale assinalar, a importante ação do Conselho Federal de Serviço Social - CFESS para a incorporação desse debate. Mediante a criação da campanha Assistentes sociais no combate ao preconceito, na gestão de 2014 - 2017, produziu-se diversificado material e iniciativas orientados a estimular o debate crítico sobre racismo, pela categoria profissional. Certamente é importante lembrar que esse é mais um movimento de materialização de um compromisso ético político assumido pela profissão e materializado no O Código de Ética Profissional do Assistente Social, aprovado em 1993, que introduziu a questão da não discriminação como um de seus princípios fundamentais. (EURICO, 2013).

Portanto, a premissa que orienta a abordagem do tema educação profissional, questão racial e Serviço Social, é a da necessidade de um aprofundamento do debate dessa questão, tendo em vista as e os assistentes sociais que trabalham com educação profissional pública, de modo a nos conduzir à uma postura crítico-investigativa acerca da totalidade e das múltiplas dimensões que a compõe. Interessa-nos especialmente refletir sobre como essa questão se apresenta como demanda aos Institutos Federais, entendendo a estrutura e superestrutura que consolidou a desigualdade racial e que engendra as condições de transformação e superação dessa situação no cotidiano profissional. 


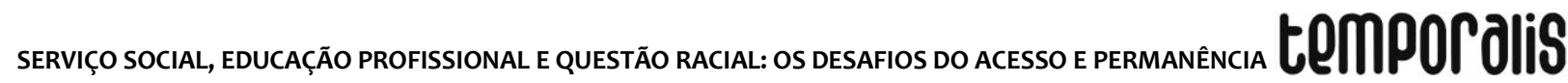

A educação profissional enquanto um espaço sócio-ocupacional do Serviço Social reflete o contexto societário, assim "Só com uma atitude teórico-metodológica plena de historicidade é possível compreender, evitando os impressionismos e as perplexidades do senso comum" (BEHRING; SANTOS, 2009, p.8), complementamos dizendo que junto a esta atitude, é preciso uma postura ético-política e técnica-operacional para compreender que "O processo é contraditório e exacerba questões que por séculos o país tenta silenciar. A tarefa é árdua, pois o racismo perpassa todas as esferas da vida cotidiana, se reproduz nas instituições e constantemente é naturalizado." (EURICO, 2013, p. 298).

\section{O ACESSO DA POPULAÇÃO NEGRA NA EDUCAÇÃO PROFISSIONAL NO BRASIL}

O acesso à educação profissional pública por parte da população negra resguarda elementos históricos; "[...] segundo os analistas da área econômica e social, o Brasil foi o país que mais cresceu, entre os anos 30 e 80 do século $X X$, com um profundo, acelerado e contundente espraiar de relações capitalistas no campo e na cidade" (BEHRING; SANTOS, 2009, p. 8). E foi neste cenário que se desenvolveu a educação profissional pública, vista como uma espécie de salvadora da pátria, objetivando conter algumas situações consideradas problemáticas no início do século XX, como a ociosidade, criminalidade e os vícios. Conforme se observa no Decreto de $n^{\circ} 7.566 / 1909$, que deu origem as escolas profissionais de artífices e ofícios, dos estudantes esperava-se que pudessem “[...] adquirir hábitos de trabalho profícuo, que os afastará da ociosidade ignorante, escola do vício e do crime; que é um dos primeiros deveres do Governo da República formar cidadãos uteis à Nação" (BRASIL, 1909, não paginado).

E assim, o acesso aos cursos por parte dos estudantes ocorria mediante a ideia de formar cidadãos úteis ${ }^{2}$ a partir do desenvolvimento de hábitos de trabalho. A educação profissional então formaria os futuros trabalhadores, mas para ingressar era necessário a comprovação da situação de pobreza, conforme descrito no artigo $6^{\circ}$,

Serão admitidos os indivíduos que o requererem dentro do prazo marcado para a matrícula e que possuírem as seguintes requisitos, preferidos os desfavorecidos da fortuna: a) idade de 10 anos no mínimo e de 13 anos no máximo; b) não sofrer o candidato moléstia infectocontagiosa, nem ter defeitos que o impossibilitem para o aprendizado do ofício (BRASIL, 1909, não paginado).

A admissão nas escolas de artífices e ofícios no passado, ocorria, assim, tendo em consideração critérios de idade (entre 10 e 13 anos), renda (deviam se encontrar em situação de pobreza) e condições de saúde (inexistência de doenças infectocontagiosas ou "defeitos"3 que dificultassem a aprendizagem), as quais excluíam um contingente significativo de pessoas. Como assinala Santos, "[...] contudo, a qualificação profissional engloba processos mais amplos que ultrapassam as questões econômicas, se fazendo presente nas relações socio-históricas" (SANTOS, 2019, p.18924)

\footnotetext{
${ }^{2} \mathrm{Na}$ obra de Sonia Marrach, ela traz a ideia de cidadão útil que significa ser genérico, universal, o ideal, um modelo burguês, bem diferente do cidadão real (MARRACH, 2009, p. 156).

3 Nota nossa: entendemos que esta nomenclatura que foi utilizada no decreto se dirigi a pessoa com deficiência e é pejorativa. No passado as pessoas negras assim como as pessoas com deficiência não tinham direitos frente ao conjunto da sociedade. Segundo Lopes, "De maneira geral o deficiente participava ativamente da vida social, desde que sua condição não fosse limitante para tal” (LOPES, 2013, não paginado).
}

Temporalis, Brasília (DF), ano 20, n. 40, p. 268-283, jul./dez. 2020. | ISSN 2238-1856 


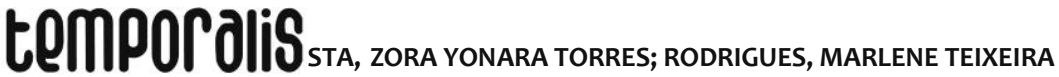

Na Primeira República, a educação profissional pública trouxe a possibilidade de fazer o povo negro ascender profissionalmente por meio da educação. Em relação as mulheres negras "[...] permanece a lacuna em relação a inclusão de mulheres negras em setores historicamente masculinos, como as funções tecnicistas e especializadas" (SOARES; SANTOS; VIRGENS, 2018, p. 685)

Apreender o letramento, ter um ofício, logicamente que não se deu de forma linear e não foi igual para homens negros e mulheres negras em nossa sociedade. Conforme descrevem Almeida e Sanchez (2016), a educação profissional pública possibilitou a escolarização dos negros, mas isso ocorreu por meio da resistência destes, significando que lutaram para permanecerem estudando, apesar da segregação racial que lhes foi imputada.

A educação profissional passou por transformações importantes nos últimos 100 anos e o padrão de ingresso, ao longo do tempo foi alterado significativamente. Da criação das 19 escolas em 1909 ao momento atual, esta realidade se transformou radicalmente. Particularmente relevante para estas mudanças foram os governos do Partido dos Trabalhadores (Lula da Silva - 2003/2011 e Dilma Roussef - 2012/2015), que, considerando a educação profissional e tecnológica uma política pública, ampliaram fortemente a rede de educação profissional, com a criação de mais de 360 unidades - os Institutos Federais, nesse período. Esta expansão dos Institutos - em 2018 totalizavam 643 unidades em funcionamento em todo o País - certamente ampliou as oportunidades de vaga à população na educação profissional pública.

Quanto à questão específica do acesso-ingresso ${ }^{4}$ das/os estudantes, hoje, a legislação estabelece que ocorra por meio de provas e por sorteio; cada Instituto Federal tem autonomia para decidir como será o processo de ingresso. Assim, existe diferentes maneiras de ingressar nas unidades sendo o processo seletivo, por meio de prova, sorteio ou avaliação de currículo do/a candidato/a à vaga.

Pensar sobre o acesso-ingresso dos estudantes que pleiteiam uma vaga na educação profissional pública é essencial para entendermos essa dinâmica. De início, é importante esclarecer que, de acordo com Silva e Veloso (2013), entende-se aqui que o acesso engloba três dimensões que são: o ingresso, a permanência e a qualidade da formação. Neste sentido, o acesso segue um fluxo: o ingresso conforme verificamos é o começo deste processo. "Assim, para analisar o acesso na sua etapa inicial (o ingresso), propõe-se a observação da oferta de vagas, do ingresso propriamente e da forma de seleção" (SILVA; VELOSO, 2013, p. 730).

Não é demais destacar que, em uma democracia capitalista a não discriminação é uma utopia, porque esta é uma sociedade baseada em contradições e antagonismos inerentes a este modo de produção, uma realidade que se faz presente também no acesso-ingresso dos estudantes negros e negras. Sendo necessário a construção de estratégias técnicopolíticas na luta cotidiana pela materialização das políticas de ação afirmativa, um campo

\footnotetext{
${ }^{4}$ Conforme Silva e Veloso nos explica "Assim, adotar o ingresso, a permanência e a qualidade na formação, alarga e aprofunda a definição do acesso, contrapondo-se a uma visão fragmentada e imediatista” (SILVA; VELOSO, 2013, p. 730).
}

Temporalis, Brasília (DF), ano 20, n. 40, p. 268-283, jul./dez. 2020. | ISSN 2238-1856 


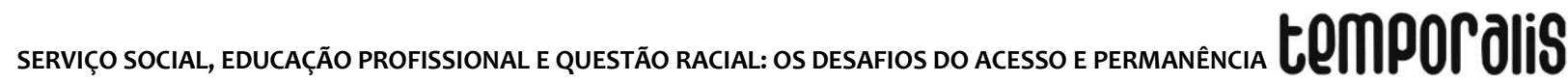

permanente de disputas, entre aqueles/as que se declararam a favor e os que discordam, em defesa da meritocracia como forma de acesso-ingresso.

Segundo Souza (2018), a política de ações afirmativas "visa contribuir na reparação de erros históricos cometidos contra os povos negros" (p. 65), assim o ingresso da população negra na educação profissional é uma forma de reparar os equívocos que o descaso e o abandono do conjunto da sociedade imprimiram ao povo negro.

A política de ação afirmativa, não surgiu no Brasil como um passo de mágica, ao contrário, foi resultado da luta dos movimentos negros para que pudéssemos reconhecer sua importância e validade. Surgindo nos Estados Unidos, a denominação ação afirmativa se espalhou pelo mundo, algumas vezes com sentido privado, outras de cunho governamental. E pensando especificamente no tema da educação profissional, como nos esclarece a pesquisadora Maria Dantas (2015).

Há um encontro do presente com o passado, tanto na perspectiva das Ações Afirmativas quanto na função social dos IFs, no sentido de reparações históricas de uma trajetória de desigualdades de oportunidades e acúmulos de desvantagens socioeconômicas e educacionais que perpassou gerações (DANTAS, 2015, p. 73).

A desigualdade racial está ligada intrinsecamente a formação socio-histórica brasileira, não temos como negar sua existência. Observemos os dados do Instituto Nacional de Estudos e Pesquisas Educacionais Aniso Teixeira (INEP), de 2019, referentes a educação profissional: o ingresso de estudantes negros e negras, indicam uma certa similitude nos números de ingressantes de acordo com a raça/cor, "[...] brancos representam 46,9\%, enquanto pretos/pardos são 52\%” (INEP, 2019). Todavia não significa que esta é a igualdade substantiva almejada, pois quando os dados são decompostos, a presença de pretos e pardos é mais significativa no acesso à educação de jovens e adultos. Além disso, há um número expressivo de negros e negras ingressantes na educação profissional, entretanto o povo negro ainda está entre os que possui níveis muito inferiores em comparação ao branco, quando se refere aos cursos superiores.

Numa sociedade capitalista, a desigualdade racial se efetiva em meio a correlação de forças entre oprimidos e opressores, desencadeada numa conjuntura perversa que diz quem poderá estudar e quem não poderá. Portanto, reconhecer a disparidade provocada pelo viés classista, racista e sexista, requer não esperar apenas pelas condições ideais, mas ter o compromisso ético em lutar para que a política de ação afirmativa, seja ferramenta efetiva no processo de reparação histórica junto ao povo negro. "Nesse sentido, o ensino não pode estar dissociado do mundo real, ou seja, das experiências sociais decorrentes da vida em comunidade e do mundo do trabalho" (SANTOS, 2019, p. 18925).

E é neste contexto que se faz urgente refletir, do ponto de vista do Serviço Social, que é chamado a participar desse processo, considerando em sua atuação a questão racial. Como pensar o acesso-ingresso na educação profissional pública das/os estudantes negros e negras e como as/os profissionais do Serviço Social intervém para além da avaliação da renda? Concordamos com Lélia, que destaca:

Enquanto a questão negra não for assumida pela sociedade brasileira como um todo: negros, brancos e nós todos juntos refletirmos, avaliarmos,

Temporalis, Brasília (DF), ano 20, n. 40, p. 268-283, jul./dez. 2020. | ISSN 2238-1856 
desenvolvermos uma práxis de conscientização da questão da discriminação racial nesse país, vai ser muito difícil no Brasil, chegar ao ponto de efetivamente ser uma democracia racial (GONZALEZ, 2018, p. 255).

\section{PERMANÊNCIA DAS/OS DISCENTES NEGROS E O SERVIÇO SOCIAL}

O que significou historicamente a permanência escolar para o povo negro? Esta resposta pode ser traduzida como algo que não está acabado, sendo um processo de avanços e retrocessos desde que foi permitido ao povo negro frequentar as escolas, com o Decreto $n^{\circ} 7.031-A$ (1878), que garantiu essa possibilidade aos adultos do sexo masculino ${ }^{5}$. Ali se inicia a luta para a permanência do povo negro nas escolas, que persiste ainda hoje, também na realidade dos Institutos Federais.

"A carnavalização das nossas relações raciais escamoteia a rigidez da segregação espacial e social que separa negros e brancos" bem destacou Sueli Carneiro (2019, p. 147). O conjunto da sociedade brasileira ainda desconhece e naturaliza a desigualdade racial, não sendo diferente em relação a permanência na educação. Como pudemos observar em nosso cotidiano profissional, em várias oportunidades, quando um discente negro ou negra interrompe seu caminhar escolar o discurso meritocrático aparece, sua não permanência é interpretada e apontada como um não esforço para concluir com êxito o curso, este pensamento imediatista está na base do senso comum, que ignora que a desigualdade racial tem a sua origem em bases estruturais e superestruturais.

A permanência na educação profissional pública, se encontra permeada de questões que devem ser pensadas pelo coletivo da sociedade. Trazemos o caso dos Institutos Federais em especial, que "[...] apesar da ampliação do binômio instituições/vagas, há problemas relacionados à permanência [...]” (MOREIRA; LAMBERT; CASTRO, 2018, p. 49), e quais seriam os problemas relacionados a permanência da população negra?

Cotidianamente, nos espaços de trabalho, as/os assistentes sociais que atuamos na educação profissional, nos deparamos com uma gama de situações que implicam na permanência ou não de discentes negros e negras, relacionadas a questões sociais, econômicas e subjetivas. Refletir deste modo sobre os processos de não permanência, evasão e expulsão do âmbito escolar é uma maneira de compreendermos que o viés racista é parte deste jogo perverso. Como destaca Grada, observar como "[...] no racismo, corpos negros são construídos como corpos impróprios, como corpos que estão 'fora do lugar' e, por esta razão corpos que não podem permanecer" (KILOMBA, 2019, p.56).

Trazemos esta ideia de não permanência escolar associada a ideia de evasão escolar, que traduzida denominamos de “'[...] expulsão do aluno da escola de forma involuntária'. Assim, percebe-se que a evasão é um processo complexo que envolve tanto questões estruturais da sociedade, quanto as relações entre alunos, professores e gestão escolar" (SANTOS, 2019, p. 18922).

\footnotetext{
${ }^{5}$ Ao grifarmos este trecho do texto, estamos indicando como a história na educação foi marcada pelo sexismo, e como nós mulheres ficamos relegadas a um destino desigual, para além do viés classista caracterizado pelo dualismo entre educação para a elite e outra para a classe de trabalhadores, como também a presença do viés racista identificado pelo cenário de desigualdade racial que só se intensificou ao longo do tempo.
}

Temporalis, Brasília (DF), ano 20, n. 40, p. 268-283, jul./dez. 2020. | ISSN 2238-1856 


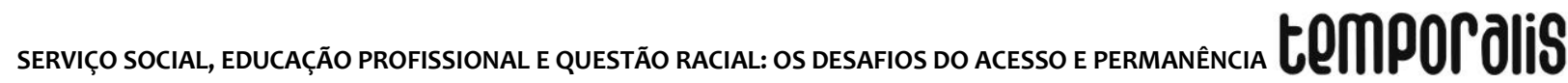

Obviamente que o racismo é estrutural e como afirmou Silvio Luiz de Almeida (2019) "[...] é um elemento que integra a organização econômica e política da sociedade” (ALMEIDA, 2019, p. 20-21), afetando a população negra de muitas formas, inclusive a sua permanência na educação.

É nesse contexto que se faz imprescindível que a categoria de profissionais do Serviço Social observe que "[...] as políticas sociais nas quais estão inseridos os assistentes sociais possuem público que tem raça predominantemente, a raça negra [...]" (MOURA, 2019, p. 193), raça não no sentido biologista, mas dentro dos parâmetros estruturais, abarcando a realidade social. Assim, concordamos com Sueli (2019) quando diz que "[...] a problemática racial requer vontade política dos governos, empresas e demais instituições da sociedade para a adoção de políticas que rompam com a apartação racial existente no Brasil" (CARNEIRO, 2019, p. 141).

Quando nos referimos a permanência das/os estudantes negras/os, podemos observar, enquanto profissionais do Serviço Social, as dinâmicas sociais que materializam a ordem vigente, o que implica algumas vezes em notarmos a presença de práticas conservadoras e autoritárias, que podem reproduzir segregações e perpetuar a desigualdade racial.

Comumente as/os assistentes sociais que trabalham na educação com a Política de Assistência Estudantil, procuram atender as demandas expressas pela população negra na escola, de modo a estabelecer uma mediação na tentativa de dirimir as dificuldades que se apresentam no cotidiano escolar. Importante destacar que a permanência das/os estudantes negras e negros vai além das questões econômicas, passando também por processos diversos como racismo, segregação, relações de poder, que algumas vezes ficam invisibilizados, pela própria crença de vivermos numa democracia racial.

Neste sentido, vale destacar novamente a série Assistente Social no Combate ao Preconceito, elaborada pelo CFESS, que apresenta um aporte importante para orientar uma práxis profissional antirracista, com um rico debate sobre concepções acerca do racismo, raça, etnia, cor e discriminação racial. Oferece assim subsídios para que o exercício profissional cotidiano se paute "[...] pela construção de outra sociabilidade, livre de preconceitos e de qualquer discriminação, justa, igualitária, verdadeiramente democrática" (ROCHA, 2016, p.16).

Operacionalizar os mínimos necessários é desafio complexo, e não podemos perder de vista as premissas inscritas no Código de Ética do Assistente Social de manter "[...] posicionamento em favor da equidade e justiça social, que assegure universalidade de acesso aos bens e serviços relativos aos programas e políticas sociais, bem como sua gestão democrática" (CFESS, [2012], p.23).

Enquanto profissional da educação, a/o assistente social é demandado/a intervir para atender questões referentes a permanência dos estudantes, atuando na operacionalização do Programa Nacional de Assistência Estudantil (PNAES) que tem como objetivos,

1 - democratizar as condições de permanência dos jovens na educação superior pública federal; II - minimizar os efeitos das desigualdades sociais e regionais na

Temporalis, Brasília (DF), ano 20, n. 40, p. 268-283, jul./dez. 2020. | ISSN 2238-1856 


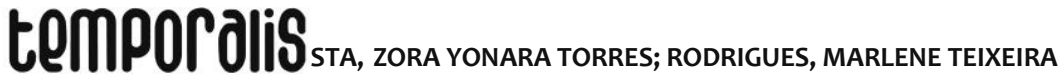

permanência e conclusão da educação superior; III - reduzir as taxas de retenção e evasão; e IV - contribuir para a promoção da inclusão social pela educação (BRASIL, 2010, não paginado).

Neste sentido, pontuamos que, a viabilização da permanência é um processo contraditório pela própria constituição da sociedade capitalista. No âmbito da educação, "[...] a forma como está regulamentado o Pnaes promove uma disputa em torno da quantidade de recursos destinados aos programas universais e seletivos, e o que prevalece é a focalização, seletividade e residualidade" (PRADA E SURDINE, 2018, p. 285). Conforme assinalado pelas autoras, “[...] a permanência possibilitada por meio do programa perpetua a lógica de desigualdade estrutural e do atendimento aos mínimos necessários de forma residual" (PRADA, SURDINE, 2018, p. 281).

Por conseguinte, a implementação da permanência para as e os estudantes negros deve ser avaliada permanentemente, considerando seus limites à promoção de uma mudança substantiva, só é possível em outra forma de sociabilidade, pautada na emancipação humana. Essa afirmativa coloca em relevo alguns elementos importantes que precisam ser problematizados em relação aos limites impostos pela realidade. $O$ fato de a permanência ser residual implica em uma incapacidade de validar uma real transformação, necessária para que as/os estudantes negros e negras concluam seus estudos com êxito. Essa constatação, entretanto, é razão adicional para romper com práticas conservadoras e autoritárias, próprias ao sistema vigente.

Compreendemos ainda que de acordo com os objetivos descritos no PNAES, a permanência estudantil envolve mais que o repasse de auxílio financeiro para os estudantes em situação de vulnerabilidade social. Necessitamos conceber condições reais para que as/os discentes negros e negras permaneçam e concluam, com sucesso os seus cursos de nível médio ou superior nos Institutos Federais.

Com isso entendemos que pertencer é um exercício e vai além da avaliação de renda, de modo que a/o discente negro se desenvolva de forma integral, contemplando não só mínimos necessários, mas trazendo à tona o debate de raça, classe e gênero, Sueli afirma que "Os esforços de integração do negro na sociedade brasileira esbarram constantemente na ausência, por parte desta mesma sociedade, de um projeto efetivo de integração social do negro" (CARNEIRO, 2019, p.15), assim permanecer no espaço escolar requer um conjunto de ações políticas, econômicas e sociais para dirimir a desigualdade racial.

No que se refere ao Instituto Federal de Brasília (IFB), a Política de Assistência Estudantil é concebida como

[...] é um conjunto de princípios e diretrizes que norteiam a implantação de ações visando a promoção do acesso, da permanência e do êxito dos estudantes na perspectiva de inclusão social, produção de conhecimento, melhoria do desempenho escolar e da qualidade de vida (IFB, 2014, p. 1).

Os princípios e diretrizes da política, enquanto um instrumento substancial para a práxis da/o assistente social nos Institutos possibilita afiançar a permanência das/os estudantes negros e negras, todavia ainda não parece ser suficiente para dirimir a não permanência nos cursos, já que "[...] o aumento da oferta de vagas para o ensino técnico e superior 


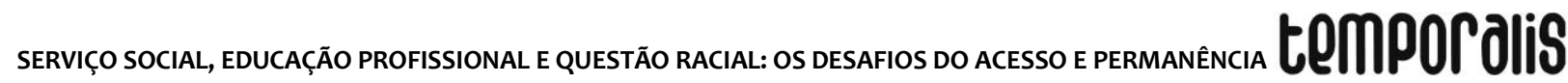

como tentativa de democratização do ensino, mas não há garantias de permanência dos estudantes na vida acadêmica." (RIBEIRO; MOREIRA, 2017, p. 41).

A dinâmica que se apresenta "[...] pressupõe considerar os indivíduos em sua vida cotidiana, espaço-tempo em que as expressões da questão social se efetivam, sobretudo, como violação dos direitos" (BEHRING; SANTOS, 2009, p. 11), analiticamente, a não permanência das/os discentes negros e negras, a saída da escola é uma violação e passa pelo desmonte da máquina pública, pelo descaso do conjunto da sociedade em naturalizar a desigualdade racial, pelos cortes orçamentários e os descompassos impetrados na sociedade atual.

As e os assistentes sociais que atuam neste espaço sócio-ocupacional devem compreender a permanência na educação profissional voltada aos estudantes negros e negras, tendo em conta que,

[...] no desenvolvimento da sociabilidade, um conjunto de contradições e o antagonismo entre as necessidades do capital e as do trabalho frustraram amplamente as promessas de liberdade e de igualdade, bem como a efetivação de uma vida social sem dominação, exploração e opressão (BEHRING; SANTOS, 2009, p. 12)

Urge, pois, aos profissionais de Serviço Social imprimir uma intervenção antirracista, de modo que a permanência dos estudantes negros e negras seja pautada na decolonialidade $^{6}$ e isso significa rompermos com processos que reproduzem e naturalizam a desigualdade racial e as relações de poder ora instituídas. Defendemos uma permanência discente sustentada por elementos antirracistas, porque,

Em tempos difíceis assim, há uma tendência contraditória para a reação, que pode se expressar na forma de imobilismo; na adesão passiva à ordem; ou na resistência, que assume direção política variada a depender do nível de organização e capacidade crítica, protagonizada pelos sujeitos coletivos (BEHRING; SANTOS, 2009, p. 16).

Ainda que os tempos sejam complexos, a categoria das/os assistentes sociais que trabalham com a educação profissional pública, precisam buscar formas de resistir à ordem vigente que cria maneiras que adensam a desigualdade racial, por isso concordamos com Márcia, que "[...] não é mais tolerável na atualidade a falta de compromisso profissional coletivo em relação à questão racial” (EURICO, 2013, p. 308). Não somente precisamos estar atentas/os as disparidades sociais e econômicas entre negros e brancos, mas compreender que a educação antirracista pode ser um caminho para repensar a permanência estudantil.

\section{CONSIDERAÇÕES FINAIS}

Ao encerrarmos este artigo, observamos que o debate acerca do acesso - ingresso e permanência das/os discentes negros e negras na educação profissional pública, implica

\footnotetext{
6 "O pensamento decolonial objetiva problematizar a manutenção das condições colonizadas da epistemologia, buscando a emancipação absoluta de todos os tipos de opressão e dominação" (REIS; ANDRADE, 2018, p. 3).
}

Temporalis, Brasília (DF), ano 20, n. 40, p. 268-283, jul./dez. 2020. | ISSN 2238-1856 


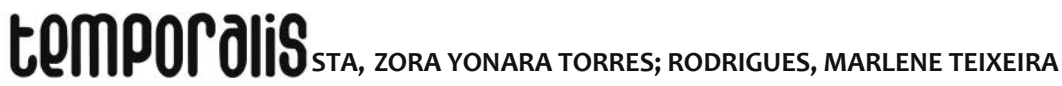

numa abordagem crítica e totalizante, considerando as múltiplas determinações no processo histórico e a dinâmica que é própria do modo de produção capitalista.

E é nesta conjuntura que as/os assistentes sociais são convocados a atuarem com suas competências e habilidades, de modo a lidar cotidianamente com contradições e antagonismos próprios do sistema vigente, a exemplo da desigualdade racial. Destaca-se que a política de ação afirmativa e a política de assistência estudantil são instrumentos importantes que as/os assistentes sociais que ocupam o espaço sócio-ocupacional da educação utilizam no seu cotidiano para realizar a intervenção profissional, tendo em vista garantir direitos e minimizar a densidade das desigualdades socialmente produzidas.

A dimensão da intervenção está suportada nos aportes teóricos-metodológicos, éticopolítico e técnico-operacional, reunindo potencialidade de saberes acadêmicos e da realidade concreta para a compreensão do que está posto. Assim, a mediação realizada pelas/os profissionais de Serviço Social no espaço sócio-ocupacional da educação profissional pública, está interligado a atual conjuntura societária.

Certamente que a intervenção das/os assistente sociais na educação profissional pública, se esbarra em entraves que historicamente identificamos o viés classista, racista e sexista. Entendemos que refletir sobre estas questões permitirá uma construção de novas formas de enfrentamento da realidade concreta. E esta não é uma tarefa fácil e não depende exclusivamente do Serviço Social, mas do conjunto da sociedade para uma real transformação da desigualdade racial.

Assim, o classismo, se apresenta na educação profissional pública desde a sua origem, com a finalidade de formar os filhos dos menos favorecidos para o trabalho. $O$ viés racista, como parte do projeto societário de dominação da elite brasileira para a manutenção das relações de poder, promoveu a subjugação e segregou a população negra, afetando no acesso - ingresso e permanência à educação e outros bens e direitos.

Em relação ao sexismo e a educação profissional, entendemos que a opressão a que mulheres negras foram e são submetidas revela a imbricação entre a desigualdade racial e de gênero. Quando as mulheres foram incluídas na educação era para apreender o modelo de educação centrado no cuidado com a família, com os afazeres da casa, para exercer suas funções domésticas. Nos dias atuais esta realidade se transformou e recentemente dados do Censo Escolar 2018, do Instituto Nacional de Estudos e Pesquisas Educacionais Anísio Teixeira (INEP), identificaram que as mulheres são maioria na educação profissional.

Não há dúvida que a educação foi e ainda é privilégio para poucos. Buscamos problematizar o acesso à educação, relacionado ao ingresso e permanência das/os discentes negros na educação profissional pública, trazendo reflexões sobre este tema, mas sabemos que este debate não está acabado.

Por muito tempo, ao falar sobre a questão racial e educação profissional pública a dificuldade que se apresentava era entender por que realizar este estudo. Para nós é essencial fazê-lo; o número ínfimo de estudos e textos sobre o tema, que encontramos durante nossa pesquisa para a materialização deste artigo retrata esta necessidade.

Temporalis, Brasília (DF), ano 20, n. 40, p. 268-283, jul./dez. 2020. | ISSN 2238-1856 
Serviço social, educação profissional e questão racial: os desafios do acesso e permanência tellpof Olif

Neste sentido entendemos que trazer este assunto é uma tentativa de descortinar o que nos pareceu ainda ser pouco discutido no espaço socioocupacional da educação onde as/os assistentes sociais trabalham. Também não temos a pretensão de esgotar este tema porque este é um campo fértil para novas articulações teóricas e acadêmicas.

Entretanto não podemos deixar de dizer que reunir autores negros nos faz pensar que nas nossas narrativas e no nosso trabalho enquanto assistentes sociais, poderíamos fazer o exercício de construir a partir de uma epistemologia negra, pois nossa formação esteve distante da contação desta história, poderíamos partir deste lugar.

"A verdade é que muitas pessoas lucram imensamente com a dominação dos outros" (HOOKS, 2019, p. 52). A dominação da população negra no Brasil é fator histórico, com raízes profundas de subjugação e segregação. Se faz presente também no processo de ingresso à educação profissional e a participação da/do assistente social nesse cenário, ancorado em um projeto ético-político profissional orientado pela defesa da liberdade e dos direitos, poderá impulsionar uma prática antirracista, ancorando-se política de ação afirmativa, expressa na Lei 12.711 de 29 de agosto de 2012 (BRASIL, 2012).

O conjunto da sociedade é responsável pela maneira como coaduna com a desigualdade racial, sabemos dos limites deste movimento, mas também a potencialidade de fazer com que o projeto societário radical seja colocado em prática. Vamos fazê-lo!

\section{REFERÊNCIAS}

ALMEIDA, Silvio Luiz de. Racismo Estrutural. São Paulo: Sueli Carneiro; Pólen, 2019. 264p.

ALMEIDA, Marco Antonio Bettine de. SANCHEZ, Livia. Os negros na legislação educacional e educação formal no Brasil. Revista Eletrônica de Educação, v. 10, n. 2, p. 234-246, 2016.

BEHRING, Eliane Rosseti; SANTOS, Silvana Mara de Morais. Questão social e direitos. In: Serviço Social: Direitos Sociais Competências Profissionais. Brasília (DF): CFESS; ABEPSS, 2009 .

BRASIL. [Constituição (1988)]. Constituição da República Federativa do Brasil de 1988. Brasília, DF: Presidência da República, [2016]. Disponível em:

http://www.planalto.gov.br/ccivil_03/constituicao/constituicao.htm. Acesso em: 9 abr. 2020.

BRASIL. Decreto $\mathbf{n}^{\circ} \mathbf{7 . 2 3 4}$, de 19 de Julho de 2010. Dispõe sobre o Programa Nacional de Assistência Estudantil - PNAES. Disponível em:

http://www.planalto.gov.br/ccivil_03/_ato2007-2010/2010/decreto/d7234.htm. Acesso em: 27 mar. 2020.

BRASIL. Decreto $n^{\circ}$ 7.566, de 23 de setembro de 1909. Escolas de Aprendizes Artificies. Cria nos capitães dos Estados da Escolas de Aprendizes Artífices, para o ensino profissional primário e gratuito. Diário Official, Rio de Janeiro, 26 set. 1909, página 6975 . (Publicação Original). Disponível em: https://www2.camara.leg.br/legin/fed/decret/190o-

Temporalis, Brasília (DF), ano 20, n. 40, p. 268-283, jul./dez. 2020. | ISSN 2238-1856 


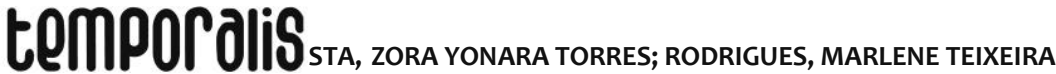

1909/decreto-7566-23-setembro-1909-525411-publicacaooriginal-1pe.html\#: :text=Decreta\%3A,ensino\%20profissional\%20primario\%20e\%20gratuito. Acesso em: 27 mar. 2020.

BRASIL. Lei de Diretrizes e Bases da Educação Nacional (LDB). Lei nº 9394, 20 de dezembro de 1996. Disponível em: http://www.planalto.gov.br/ccivil_03/leis/l9394.htm. Acesso em: 10 abr. 2020.

BRASIL. Lei 12.711 de 29 de agosto de 2012. Dispõe sobre o ingresso nas universidades federais e nas instituições federais de ensino técnico de nível médio e dá outras providências. Disponível em: http://www.planalto.gov.br/ccivil_03/_ato20112014/2012/lei/l12711.htm. Acesso em: 10 abr. 2020.

CARNEIRO, Sueli. Escritos de uma vida. São Paulo: Pólen Livros, 2019. 296p.

CFESS. Código de ética do/a assistente social. Lei 8.662/93 de regulamentação da profissão. $10^{a}$. ed. rev. e atual. Brasília (DF), [2012]. 60 p.

DANTAS, Maria José Pereira. Ações afirmativas na educação profissional técnica de nível médio: um estudo no IFPB - Campus João Pessoa. 2015. Dissertações (Mestrado em Gestão Pública para o Desenvolvimento do Nordeste)-Programa de Pós-Graduação em Gestão Pública para o Desenvolvimento do Nordeste)-Universidade Federal de Pernambuco, Recife, 2015.

EURICO, Márcia Campos. A percepção do assistente social acerca do racismo institucional. Serv. Soc. Soc., São Paulo, n. 114, p. 290-310, abr./jun. 2013.

GONZALEZ, Lélia. Primavera para as rosas negras: Lélia em primeira pessoa. Diáspora Africana: Editora Filhos da África, 2018. 486p.

GOUVEIA, Fernanda Paixão de Souza. A expansão dos Institutos Federais de Educação, Ciência e Tecnologia no território brasileiro: entre o local e o nacional. Espaço e Economia: Revista Brasileira de Geografia Econômica, Rio de Janeiro: Universidade Estadual do Rio de Janeiro; Seropédica: Universidade Federal Rural do Rio de Janeiro, ano 5, n. 9, 2016. Disponível em: https://journals.openedition.org/espacoeconomia/2434. Acesso em: 10 abr. 2020.

HOOKS, Bell. Olhares negros: raça e representação. São Paulo: Elefante, 2019. 356p.

IAMAMOTO, Marilda. A questão Social no Capitalismo. Revista Temporalis, Brasília (DF): Associação Brasileira de Ensino e Pesquisa em Serviço Social, ano 2, n. 3, jan./jul. 2001.

IBGE. Diretoria de Pesquisas, Coordenação de População e Indicadores Sociais.

Desigualdades sociais por cor ou raça no Brasil. Estudos e Pesquisas: Informação demográfica e econômica, Brasília (DF): IBGE, n. 41, 2019. Disponível em: https://biblioteca.ibge.gov.br/visualizacao/livros/liv101681_informativo.pdf. Acesso em: 20 mar. 2020. 
Serviço social, educação profissional e questão racial: os desafios do acesso e permanência tompôj]

IBGE. Diretoria de Pesquisas, Coordenação de Trabalho e Rendimento. PNAD Contínua. Educação 2018. Brasília (DF), 2019. Disponível em:

https://biblioteca.ibge.gov.br/visualizacao/livros/liv101657_informativo.pdf. Acesso em: 29 mar. 2020.

IBGE. PNAD Contínua 2018: educação avança no país, mas desigualdades raciais e por região persistem. Agência de Notícias IBGE, 19 jun. 2019. Disponível em: https://agenciadenoticias.ibge.gov.br/agencia-sala-de-imprensa/2013-agencia-denoticias/releases/24857-pnad-continua-2018-educacao-avanca-no-pais-mas-desigualdadesraciais-e-por-regiao-persistem. Acesso em: 29 mar. 2020.

IFB. Política de Assistência Estudantil do Instituto Federal de Educação, Ciência e Tecnologia de Brasília. Brasília (DF), [2014]. Disponível em: https://www.ifb.edu.br/attachments/article/6397/POLÍTICA\%20DE\%20ASSISTÊNCIA\%20EST UDANTIL333.pdf. Acesso em: 27 mar. 2020.

INEP. Educação profissional cresce em 2019 e alcança 1,9 milhão de matriculados; mulheres são maioria. Disponível em: http://inep.gov.br/artigo/lasset_publisher/B4AQV9zFY7Bv/content/educacao-profissional-cresce-em-2019-ealcanca-1-9-milhao-de-matriculados-mulheres-sao-maioria/21206. Acesso em: 24 mar. 2020.

KILOMBA, Grada. Memórias de uma plantação: episódios de racismo cotidiano. Tradução Jess Oliveira. Rio de Janeiro: Cobogó, 2019. 248 p.

LOPES, Gustavo Casimiro. O preconceito contra o deficiente ao longo da história. Disponível em: https://www.efdeportes.com/efd176/o-deficiente-ao-longo-dahistoria.htm. FDeportes.com, Revista Digital, Buenos Aires, año 17, n. 176, Enero 2013. http://www.efdeportes.com/. Acesso em: 1 abr. 2020.

MANFREDI, Silvia Maria. Educação Profissional no Brasil. São Paulo: Cortez, 2002.

MARRACH, Sonia. Outras histórias da educação: do iluminismo à indústria cultural (1823 a 2005). São Paulo: Ed. Unesp. 2009.

MOREIRA, Larici Keli Rocha. LAMBERT, Aline dos Santos. CASTRO, Regina Celi Alvarenga de Moura. Educação Profissional e Tecnológica: Permanência e evasão em foco. Rev. Bra. Edu. Saúde, v. 8, n. 4, p. 48-53, out./dez. 2018.

MOURA, Luana Rocha da Silva. A construção da política de ações afirmativas no instituto Federal do rio Grande do Sul e o Serviço Social. In: DUARTE, Amanda Machado do Santos, et al., (Orgs.). Serviço Social e educação profissional e tecnológica. São Paulo: Cortez, 2019.

PRADA, T.; SURDINE, M. C. DA C. A assistência estudantil nos Institutos Federais de Educação, Ciência e Tecnologia. SER Social, Brasília (DF), v. 20, n. 43, p. 268-289, 13 nov. 2018. 
REIS, Maurício de Novais; ANDRADE, Marcilea Freitas Ferraz de. O pensamento decolonial: análise, desafios e perspectivas. Revista Espaço Acadêmico, Maringá, n. 202, mar. 2018.

RIBEIRO, Jefferson Bruno Pereira. MOREIRA, Jonathan Rosa. Fatores sociais e acadêmicos na evasão escolar do curso técnico em segurança do trabalho do polo Itapoã do Instituto Federal de Brasília. Revista Eixo, Brasília (DF): Instituto Federal de Educação, Ciência e Tecnologia de Brasília/IFB, v. 6, n. 2, p. 40-47, jul./dez. 2017.

ROCHA, Roseli. Série assistente social o combate ao preconceito. Brasília (DF): CFESS, 2016. (Caderno 3, Racismo).

SANTOS, Dionys Morais dos. Evasão escolar na EJA: estudo comparativo em uma escola da rede pública estadual de Pacatuba - CE. Braz. J. of Develop., Curitiba, v. 5, n. 10, p. 18916-18940, oct. 2019.

SILVA, Geraldo da. ARAÚJO, Marcia. Da interdição escolar às ações educacionais de sucesso: escolas dos movimentos negros e escolas profissionais, técnicas e tecnológicas. In: ROMÃO, Jeruse (Org.). História da Educação do Negro e outras histórias. Brasília (DF): Ministério da Educação. Secretaria de Educação Continuada, Alfabetização e Diversidade,2005.

SILVA, Maria das Graças Martins da. VELOSO, Tereza Christina Mertens Aguiar. Acesso nas políticas da educação superior: Dimensões e indicadores em questão. Avaliação, Campinas, Sorocaba, v. 18, n. 3, p. 727-747, nov. 2013

SOARES, C. C. M.; SANTOS, P. P. F. DOS; VIRGENS, A. M. DAS. Mulher negra no mundo do trabalho. Linhas Críticas, Brasília (DF), v. 23, n. 52, 7 dez. 2018.

SOUZA, Izanete Marques. Permanência e êxito nos cursos técnicos: desafios e conquistas. Curitiba: Appris, 2018.

Zora Yonara Torres Costa Trabalhou na análise e interpretação dos dados, assim como na redação do artigo.

Assistente Social. Doutoranda em Política Social. Instituto Federal de Educação, Ciência e Tecnologia de Brasília (IFB) e Universidade de Brasília (UnB). Doutoranda pelo Programa de Pós-Graduação em Política Social (PPGPS), Departamento de Serviço Social, Instituto de Ciências Humanas da Universidade de Brasília (SER/IH/UnB). Líder do Grupo de Pesquisa Diversidade e Inclusão (IFB) e integrante do GENPOSS Grupo de estudo e pesquisa em Gênero, Política Social e Serviços Sociais. Departamento de Serviço Social. UnB, Campus Universitário Darcy Ribeiro, Instituto Central de Ciências.

Marlene Teixeira Rodrigues Trabalhou na revisão crítica e aprovação da versão a ser publicada.

Assistente Social. Professora. Programa de Pós-Graduação em Política Social - Universidade de Brasília (UnB). Pós-Doutora em Sociologia (Universidade de Barcelona), Doutora em Sociologia e Mestra em Política Social (Universidade de Brasília). Assistente Social (Universidade Federal de Juiz de Fora). Departamento de Serviço Social. UnB, Campus Universitário Darcy Ribeiro, Instituto Central de Ciências.

Temporalis, Brasília (DF), ano 20, n. 40, p. 268-283, jul./dez. 2020. | ISSN 2238-1856 